\title{
Article \\ Glucose Induces Thylakoid Formation and Upregulates Green Pigment Contents in Complete Dark Culture of the Angiosperm Pachira macrocarpa
}

\author{
Tzan-Chain Lee ${ }^{1,+} \oplus^{\infty}$, Kuan-Hung Lin ${ }^{2,+} \mathbb{\infty}$, Meng-Yuan Huang ${ }^{3, *} \mathbb{C}$ and Chi-Ming Yang ${ }^{4, *}$ \\ 1 Department of Tea Science, Anxi College of Tea Sciences, Fujian Agriculture and Forestry University, \\ Fuzhou 350002, China; crane173@yahoo.com.tw \\ 2 Department of Horticulture and Biotechnology, Chinese Culture University, Shilin, Taipei 11114, Taiwan; \\ rlin@faculty.pccu.edu.tw \\ 3 Department of Life Sciences and Innovation and Development Center of Sustainable Agriculture, \\ National Chung Hsing University, Taichung 40227, Taiwan \\ 4 Biodiversity Research Center, Academia Sinica, Nangang, Taipei 11529, Taiwan \\ * Correspondence: hmy6@nchu.edu.tw (M.-Y.H.); cmyang@gate.sinica.edu.tw (C.-M.Y.); \\ Tel.: +886-2787-1096 (C.-M.Y.) \\ + These authors contributed equally to this work.
}

Citation: Lee, T.-C.; Lin, K.-H.; Huang, M.-Y.; Yang, C.-M. Glucose Induces Thylakoid Formation and Upregulates Green Pigment Contents in Complete Dark Culture of the Angiosperm Pachira macrocarpa. Agronomy 2021, 11, 1746. https:// doi.org/10.3390/agronomy11091746

Academic Editor: Giovanni Caruso

Received: 7 July 2021

Accepted: 28 August 2021

Published: 30 August 2021

Publisher's Note: MDPI stays neutral with regard to jurisdictional claims in published maps and institutional affiliations.

Copyright: (c) 2021 by the authors. Licensee MDPI, Basel, Switzerland This article is an open access article distributed under the terms and conditions of the Creative Commons Attribution (CC BY) license (https:// creativecommons.org/licenses/by/ $4.0 /)$

\begin{abstract}
In addition to angiosperms, most plants are able to synthesize chlorophyll (Chl)-generating green tissues in total darkness. In this study, 140 plants of the angiosperm Pachira macrocarpa were divided into five groups. Among them, one group was grown for 2 weeks under natural light conditions, whereas the others were grown in complete darkness $\left(0 \mu \mathrm{mol} \mathrm{m}^{-2} \mathrm{~s}^{-1}\right)$. Dark-grown plants were then treated with $0 \sim 6 \%$ glucose for another 8 weeks. The budding and greening ratios, ultrastructure of chloroplasts (ChlPs) of newly developed leaves, and green pigment contents of pre-illuminated mature and young leaves, and totally dark-grown newly developed leaves were measured. Results showed that glucose inhibited the budding and promoted the greening of newly developed leaves. Pre-illuminated mature and young leaves were able to synthesize green pigments during the 2 weeks of dark adaption. Dark-grown newly developed leaves contained high levels of green pigments at 2 and 3 weeks after budding. Green pigments of glucose-fed newly developed leaves had increased, whereas they had decreased in control leaves. In addition, ChlPs of darkgrown glucose-fed newly developed leaves contained both giant grana and prolamellar bodies (PLBs), usually found in shade plants and etiolated seedlings, respectively. The higher the glucose concentration was, the greater the numbers of grana, thylakoids, and PLBs. Glucose increased the green pigment contents and grana formation in newly developed leaves in a dark condition, and the mechanisms are discussed.
\end{abstract}

Keywords: angiosperm; chloroplast development; dark culture; glucose; thylakoid

\section{Introduction}

Chloroplasts (ChlPs) harbor the photosynthetic apparatus, containing chlorophylls (Chls), pigment-protein complexes, and the thylakoid system. In ChlPs of higher plants, $\mathrm{Chl}$ biosynthesis requires light, and the limiting step is the transfer of the protochlorophyllide (Pchlide) metabolite to chlorophyllide (Chlide) by light-dependent Pchlide oxidoreductase (POR; LPOR), when the protein structure changes and reduces nicotinamide adenine dinucleotide phosphate (NADPH) oxidation to synthesize Chlide [1,2]. Chls, which are responsible for light absorption that initiates photosynthesis, are the most abundant green pigments in nature. It is well known that cyanobacteria, algae, mosses, ferns, and gymnosperms are able to synthesize $\mathrm{Chl}$ in complete darkness by utilizing dark POR $(D P O R)$ [3-5]. In contrast, many angiosperm seedlings are etiolated in completely dark growth conditions due to a lack of DPOR genes [6]. Surprisingly, algal cells can be cultured 
and survive under dark conditions if fed glucose, sucrose, or glycerol as carbon sources, and they synthesize Chl using their DPOR genes [6,7]. However, whether other green pigments can be synthesized in angiosperms under dark conditions while being fed glucose still remains unknown.

Glucose and sucrose can act as signal transduction intermediates, and they coordinate expressions of the plasteome and nuclear-encoded photosynthetic genes. For example, an abscisic acid (ABA) receptor, pyrabactin resistance-like 8 (PYL8), is responsive to glucose, and it responds by upregulating translational levels in glucose-fed plants [8]. A high glucose concentration $(6 \%)$ in a dark condition can cause accelerated leaf yellowing and senescence in Arabidopsis leaves [9]. However, an exogenous supply of moderate concentrations of sucrose or glucose $(50 \mathrm{mM})$ rescued the high light-dependent growth and high-Chl fluorescence phenotypes of adg1-1/tpt-2 double-mutant plants [10]. Many angiosperms need to be pre-illuminated before they can synthesize $\mathrm{Chl}$ in complete darkness [11,12]. Previously, we reported that large variations in chlorophyllase (Chlase) activity existed in seven all-green plants, and Pachira macrocarpa contained significantly higher Chlase activity compared to the other plants [13]. Moreover, the messenger (m)RNA and protein levels of $P$. macrocarpa chlorophyllases $(P m C L H s)$ are unequally expressed in young and old leaves [14]. In this study, we substituted glucose for photosynthesis as a carbon resource in a dark condition. We demonstrated that pre-illuminated mature and young leaves of P. macrocarpa were able to synthesize green pigments (that possibly included intermediates of Chl biosynthesis or other compounds) and maintained the green level in complete darkness after being fed glucose. In addition, totally dark-grown newly developed leaves could also synthesize green pigments in complete darkness without illumination. Glucose dramatically affected the abilities to develop ChlPs and synthesize green pigments under dark conditions in this angiosperm.

\section{Material and Methods}

\subsection{Plant Materials, Cultural Practices, and Glucose Treatments}

Pachira macrocarpa plants were purchased from local gardens in Taipei, Taiwan, for our experiments. In total, 145 plants at $45 \mathrm{~cm}$ in height were selected and placed in a greenhouse. Plants were evenly spaced to encourage similar growth rates and sizes. Plants were watered three times a week, and those of a uniform size were then chosen and randomly separated into five groups for the following experiments. One group of plants was grown under outdoor conditions as the control, and the other four groups of plants were transferred to a totally dark room $(9 \times 3 \times 2 \mathrm{~m})$ and grown in complete darkness $\left(0 \mu \mathrm{mol} \mathrm{m} \mathrm{m}^{-2} \mathrm{~s}^{-1}\right)$ for 2 weeks. During the 2-week period, dark-grown plants were treated with nutrient solutions containing $0 \%, 2 \%, 4 \%$, or $6 \%$ glucose $\left(50 \mathrm{ml} \mathrm{day}^{-1}\right.$ plant $\left.^{-1}\right)$ and continued to be fed the nutrient solutions for 4-, 6-, and 8-week periods. All plants were fed $50 \mathrm{~mL}$ of nutrient solution each day. One hundred liters of nutrient solution contained $50 \mathrm{~g}$ $\left.\mathrm{MgSO}_{4}, 52 \mathrm{~g} \mathrm{Ca}_{2} \mathrm{H}_{2} \mathrm{PO}_{4}\right), 81 \mathrm{~g} \mathrm{KNO}_{3}, 32 \mathrm{~g} \mathrm{NH}_{4} \mathrm{NO}_{3}, 2 \mathrm{~g} \mathrm{H}_{3} \mathrm{BO}_{3}, 0.05 \mathrm{~g} \mathrm{ZnSO}_{4}, 1 \mathrm{~g} \mathrm{MnSO}$, $0.05 \mathrm{~g} \mathrm{CuSO}_{4}$, and $0.05 \mathrm{~g} \mathrm{NaMoO}_{4}$ modified from Johnson's solution [15]. Pre-illuminated mature and young leaves and totally dark-grown newly developed leaves were recorded and characterized in each experiment. All of the following procedures were conducted under dim green light.

\subsection{Determination of Total Green Pigments}

Following extraction of a liquid nitrogen-dried leaf with $80 \%(v / v)$ acetone, green pigments were determined according to a spectrophotometric method [16]. Absorbances at 663.6 and $646.6 \mathrm{~nm}$ were measured with a UV-visible spectrophotometer (Hitachi U2000, Tokyo, Japan).

\subsection{Ultrastructure of the Thylakoid System}

Leaves were collected, cut into small cubes, and fixed in $2.5 \%$ glutaraldehyde for $2 \mathrm{~h}$ at $4{ }^{\circ} \mathrm{C}$ in $0.1 \mathrm{M}$ cacodylate buffer ( $\mathrm{pH}$ 7.0). Samples were washed three times for $15 \mathrm{~min}$ each 
in $0.1 \mathrm{M}$ cacodylate buffer ( $\mathrm{pH} 7.0$ ) at $4{ }^{\circ} \mathrm{C}$, and then post-fixed in $1 \%$ aqueous osmium tetroxide in $0.1 \mathrm{M}$ cacodylate buffer ( $\mathrm{pH} 7.0$ ) for $2 \mathrm{~h}$, followed by three washes for $15 \mathrm{~min}$ each with the same buffer. Tissues were dehydrated in a graded ethanol series, infiltrated and embedded in pure Spurr's resin, and polymerized at $70{ }^{\circ} \mathrm{C}$ for $8 \mathrm{~h}$. Ultrathin gold sections were cut on a Reichert-Jung ultra-microtome (Ultracut E, Leica, Vienna, Austria), collected on formvar-coated grids, stained with a saturated solution of uranyl acetate in $100 \%$ ethanol, and post-stained with lead citrate. Observations were made with an H-600 transmission electronic microscope (TEM, Hitachi, Tokyo, Japan).

\section{Results}

\subsection{Color of P. macrocarpa Leaves under Dark Culture}

All of the P. macrocarpa leaves were green before being cultured in complete darkness (Figure 1a). The mature leaves without glucose feeding became a pale-yellow color (Figure 1b), and newly developed leaves of 2- and 3-week dark-grown control plants (without glucose feeding) were a green-tinted color Figure 1c). However, the size of newly developed leaves of $6 \%$ glucose-fed plants appeared small but fresh green (Figure 1f). The gradient of glucose concentrations (Figure 1 $\mathrm{c}-\mathrm{f}$ ) resulted in a gradient of green color in darkgrown newly developed leaves, indicating that newly developed leaves of dark-grown plants had synthesized some green pigments during the 2 weeks, but these leaves were unable to continue this biochemical phenomenon in complete darkness. In addition, expansion of mature leaves diluted the green pigment contents resulting in a pale-yellow color.

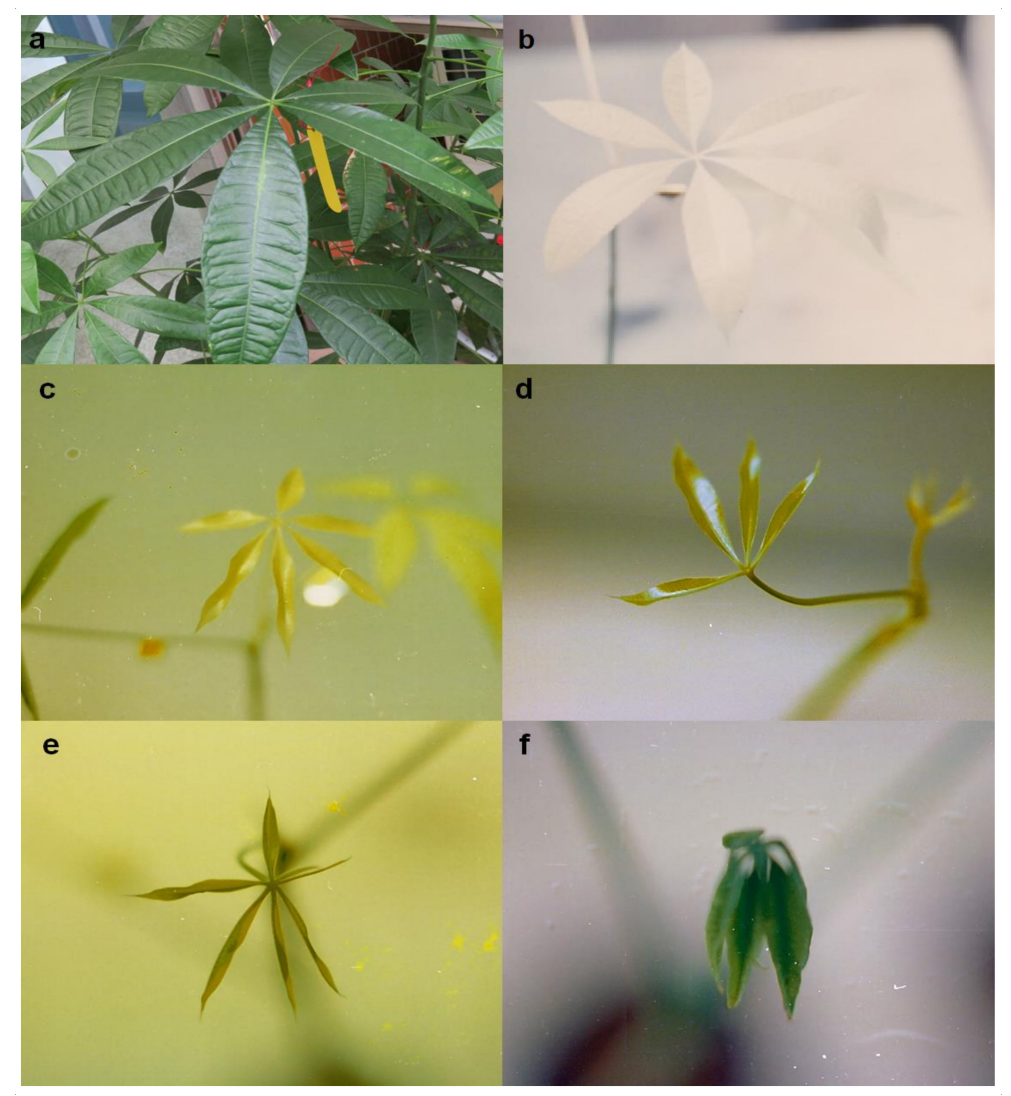

Figure 1. Two- and 3-week-old newly developed leaves of dark-grown Pachira macrocarpa plants fed various concentrations of glucose. The pictures were taken within $15 \mathrm{~s}$ after exposure to natural light. Mature leaves of test plants cultured in a light condition (a), and in a dark condition (b) without glucose treatments. Newly developed leaves of dark-grown P. macrocarpa plants cultured in dark conditions and fed $0 \%$ (c), $2 \%$ (d), $4 \%$ (e), and 6\% (f) glucose. 


\subsection{Green Ratio of Newly Developed Leaves of P. macrocarpa Plants Grown in Darkness}

The greening and pale-yellowing ratios of totally dark-grown newly developed leaves were examined during 4-, 6-, and 8-week growth periods (Figure 2). Green (including green-tinted color) ratios of newly developed leaves of test plants treated with $0 \%$ (control), $2 \%$, and $4 \%$ concentrations of glucose were $<10 \%, 47 \sim 60 \%$, and $67 \sim 80 \%$, respectively. Nevertheless, those plants treated with a $6 \%$ concentration of glucose produced $100 \%$ newly developed green leaves. The higher the glucose concentration was, the higher the green ratio of newly developed leaves was we observed, implying that glucose inhibited the newly developed leaves grown in complete darkness, but enhanced greening of newly developed leaves.

\section{Glucose concentration $(\%)$}

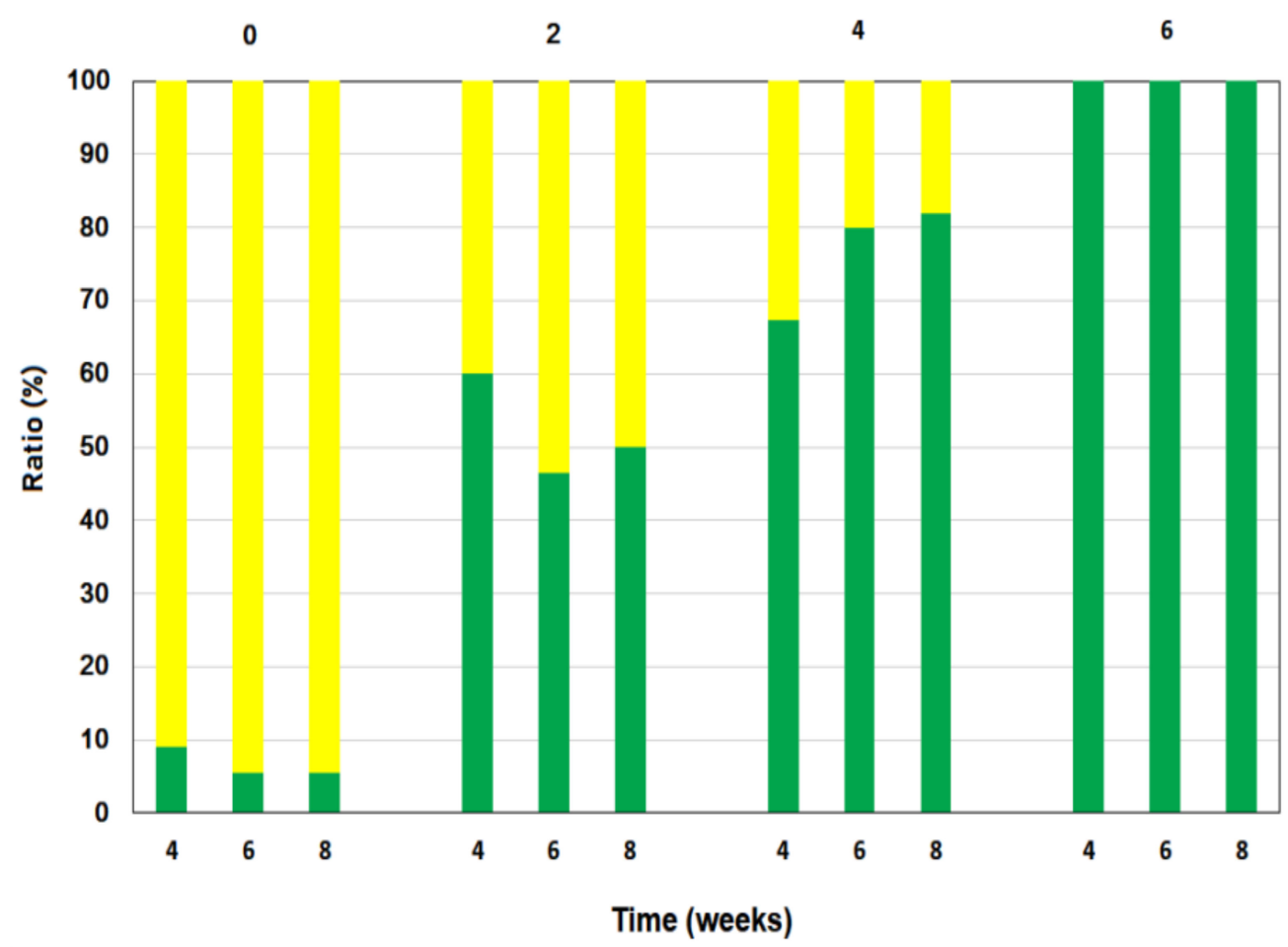

Figure 2. Greening (including green-tinted color) ratio of newly developed leaves of Pachira macrocarpa plants grown in complete darkness. Green bar, green leaf ratio; yellow bar, pale-yellow leaf ratio.

\subsection{Green Pigments in Pre-Illuminated Mature and Young Leaves of P. macrocarpa}

Green pigments of pre-illuminated mature and young leaves were determined at 2-week intervals after the leaves were transferred to darkness (Figure 3). All of the green pigment experiments were conducted under dim green light. In Figure 3a, the relative green pigments of mature leaves grown for a 2-week period in complete darkness dropped to $97.5 \%$ compared to light-grown plants at $105 \%$ in control plants, suggesting that the synthesis and degradation of green pigments remained somewhat balanced after 2 weeks in complete darkness, and those pre-illuminated mature leaves could still maintain green pigments in complete darkness for 2 weeks. Moreover, green pigment contents of darkgrown plants fed $2 \%, 4 \%$, and $6 \%$ glucose were significantly higher than that of non-glucose treated plants (control) in the dark, indicating that glucose increased synthesis of green pigments in pre-illuminated mature leaves grown in complete darkness for 2 weeks. In the 4 -week period, the relative green pigment contents reached $138 \%$ compared to the control, and that of dark-grown plants fed $6 \%$ glucose was similar to that of light-treated control plants. The increase in the green pigment content caused by glucose remained for 
4 weeks and then began to decline, as observed in pre-illuminated mature leaves. Although green pigment contents of all dark-grown plants decreased sharply after 4 weeks, levels (70 85\%) of glucose-fed plants were significantly higher than that of dark-grown control plants $(48 \%)$ after the 6-week period. This suggests that glucose delayed the degradation of green pigments in pre-illuminated mature leaves grown in complete darkness during the time course of this research.
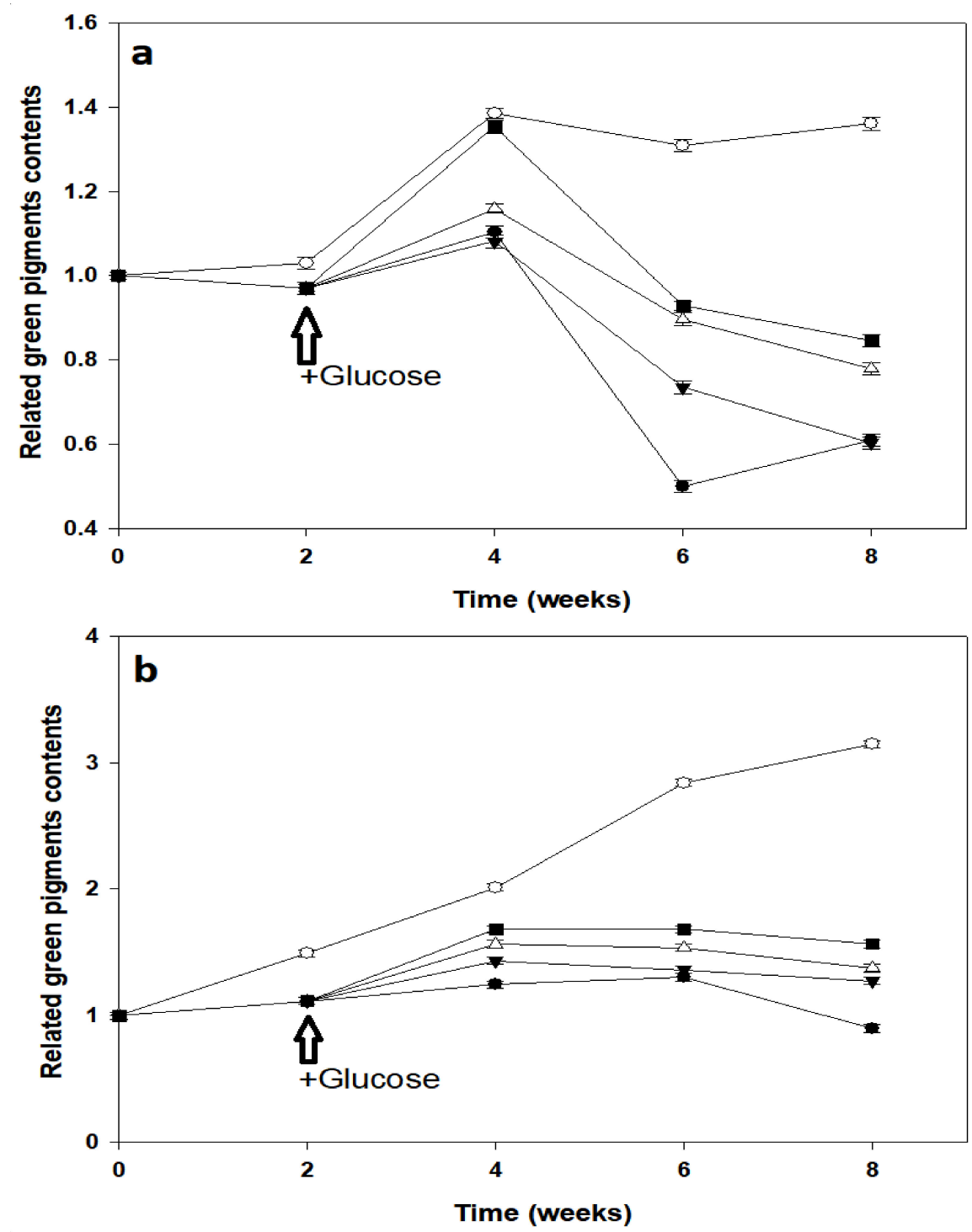

Figure 3. Variations in relative green pigment contents of pre-illuminated mature (a) and young (b) leaves of Pachira macrocarpa plants after feeding $0 \%(\bullet), 2 \%(\nabla), 4 \%(\triangle)$, and $6 \%(\boldsymbol{\square})$ glucose in complete darkness and in a lighted condition $(\bigcirc)$. Each data point represents the mean \pm SD of five independent measurements.

In Figure 3b, green pigment contents of pre-illuminated young leaves in a dark condition were significantly lower than those of leaves in a light condition. After 2 weeks of light and dark adaptation, relative green pigment contents of young leaves in lightgrown and dark-grown plants increased to about $149 \%$ and $112 \%$, respectively, compared to the controls. Furthermore, increases in the relative green pigment contents of all preilluminated young leaves were observed throughout the 6-week period, and then slowly declined to the end of the experiment, suggesting that young leaves were able to synthesize and accumulate green pigments in complete darkness for 6 weeks. Four weeks after feeding 
glucose, green pigment contents of all glucose-fed plants were significantly higher than those of control plants under a dark condition.

\subsection{Green Pigment Contents of Newly Developed Leaves of P. macrocarpa}

Figure 4 demonstrates that green pigment contents of glucose-fed plants were significantly higher than those of dark-grown control plants, but lower than those of light-grown plants in each time period. During the experimental time course, all green pigment contents of newly developed leaves under darkness were dramatically promoted by glucose for 5 weeks, suggesting that newly developed leaves could synthesize green pigments.

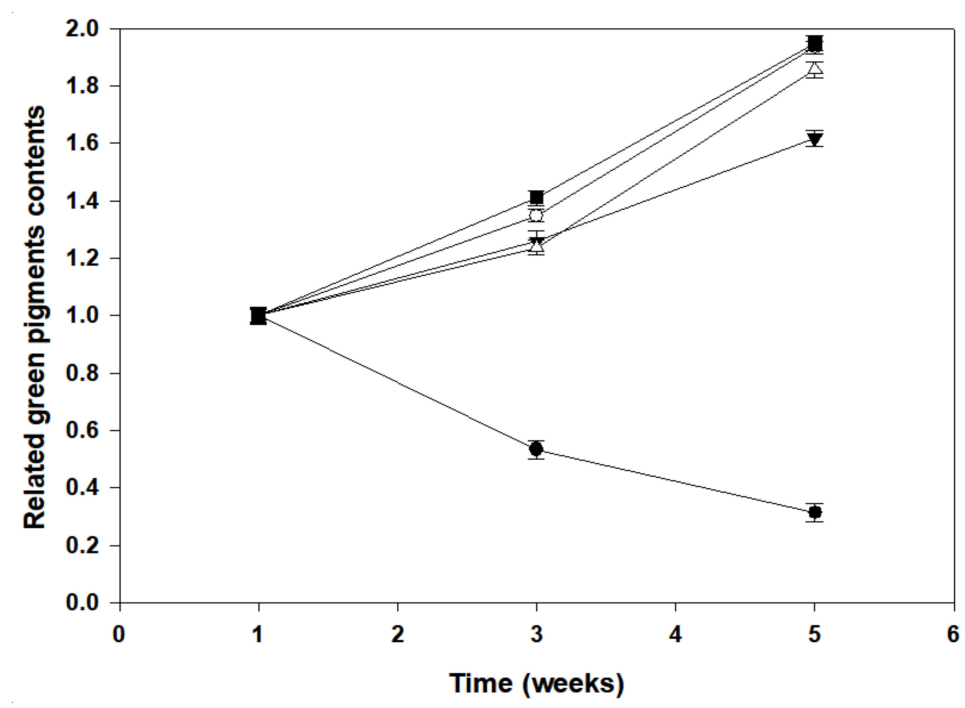

Figure 4. Variations in relative green pigment contents of newly developed leaves of Pachira macrocarpa plants fed $0 \%(\bullet), 2 \%(\nabla), 4 \%(\triangle)$, and $6 \%(\boldsymbol{\square})$ glucose in complete darkness and in a lighted condition $(\bigcirc)$. Each data point represents the mean \pm SD of five independent measurements.

To examine the effect of glucose on the recovery capacity of newly developed fresh leaves of dark-grown control plants, 16 plants grown for 8 weeks in complete darkness were divided into four equal groups. Among them, one group was transferred to a natural illumination condition and the other three groups remained in complete darkness and were respectively fed $0 \%, 4 \%$, and $8 \%$ concentrations of glucose for an additional 2 weeks (Figure 5). Relative green pigment contents (with respect to that without glucose feeding) of fresh leaves fed $4 \%$ and $8 \%$ glucose were $283 \%$ and $228 \%$, respectively.

\subsection{Budding Ratios of Newly Developed Leaves of P. macrocarpa in Dark Culture}

Eight weeks after test plants were transferred to complete darkness, budding ratios of newly developed leaves fed $0 \% \sim 6 \%$ concentrations of glucose are shown in Figure 6. Budding ratios of those totally dark-grown plants treated with $2 \%, 4 \%$, and $6 \%$ glucose were $75 \%, 60 \%$, and $55 \%$, respectively, compared to that of dark-grown control plants $(0 \%$ glucose). Apparently, the higher the glucose concentration was, the lower the budding ratio was, indicating that glucose inhibited the budding of newly developed fresh leaves in complete darkness.

\subsection{Ultrastructure and Morphology of the Thylakoid System in Mesophyll Cells from Newly Developed Leaves}

Central parts of light- or dark-grown leaves fed various concentrations of glucose were sampled to study the ultrastructure and morphology of thylakoid membranes (Figure 7). Figure 7a,b show ChlPs of 3-week-old newly developed leaves of light-grown control plants that contained a normal thylakoid ultrastructure, usually found in other sun plants. Darkgrown plants contained many PLBs (Figure 7c,e,h,i), usually found in etioplasts of etiolated seedlings, and also contained giant grana, usually found in shade plants (Figure $7 \mathrm{~g}-\mathrm{j}$ ). 
However, numbers of paired thylakoid membranes per granum in ChlPs of dark-grown plants were proportional to the green pigment contents and its related pigment-protein complexes, which were promoted by glucose in complete darkness. Grana in ChlPs of dark-grown control plants contained four layers of thylakoid membranes (Figure 7c,d; the numbers of thylakoid layers are indicated by white numbers), and that of $2 \%$ glucose-fed plants contained 11 layers of thylakoid membranes (Figure 7f), similar to that of normal plants (Figure $7 \mathrm{a}, \mathrm{b}$ ). ChlPs of $4 \%$ and $6 \%$ glucose-fed plants contained many giant grana connected with PLBs that were not found in other kinds of ChlPs (Figure 7g-j). While there were more thylakoid layers in dark-grown plants than in the light-grown plants, the length of grana in the former was shorter than that in the latter.

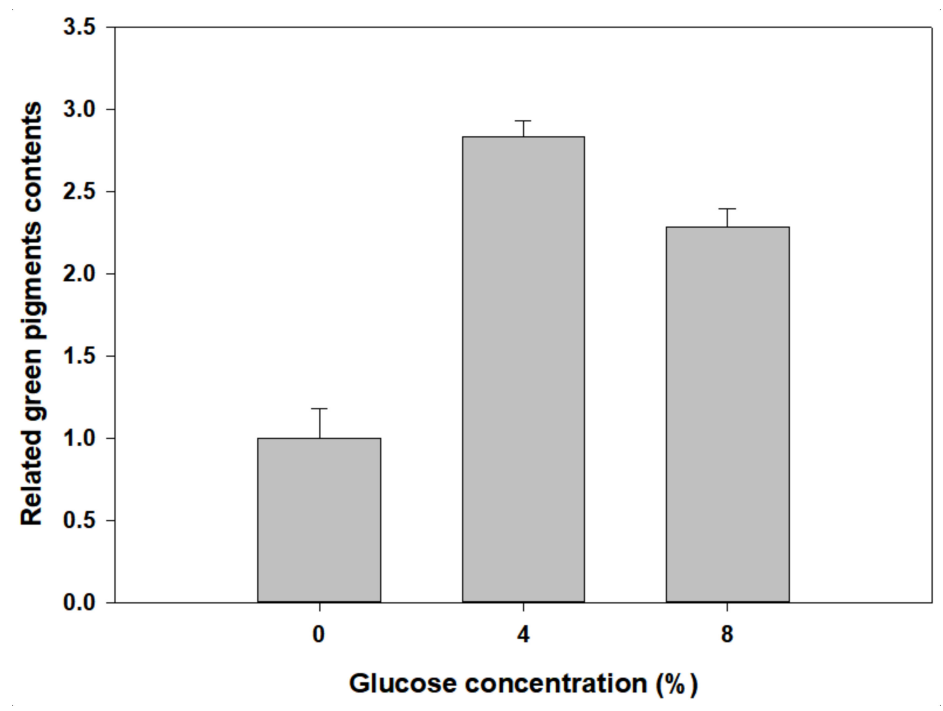

Figure 5. Variations in relative green pigment contents of $0 \%$ glucose-fed newly developed leaves of Pachira macrocarpa plants transferred to 0-8\% glucose for another 2 weeks in complete darkness. Each data point represents the mean $\pm \mathrm{SE}$ of four plants.

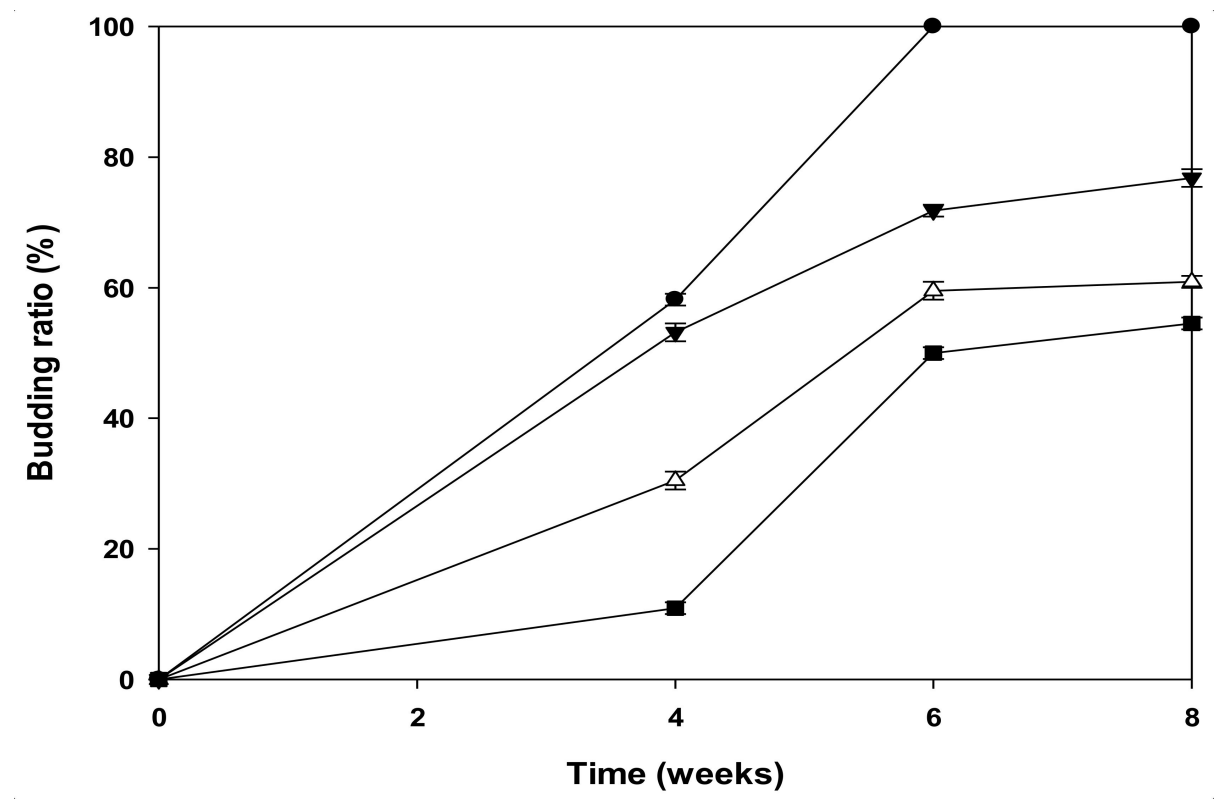

Figure 6. Budding ratios of newly developed leaves of Pachira macrocarpa plants grown in complete darkness and fed $0 \%(\bullet), 2 \%(\nabla), 4 \%(\triangle)$, and $6 \%(\square)$ glucose. Each data point represents the mean $\pm \mathrm{SD}$ of five independent measurements. 

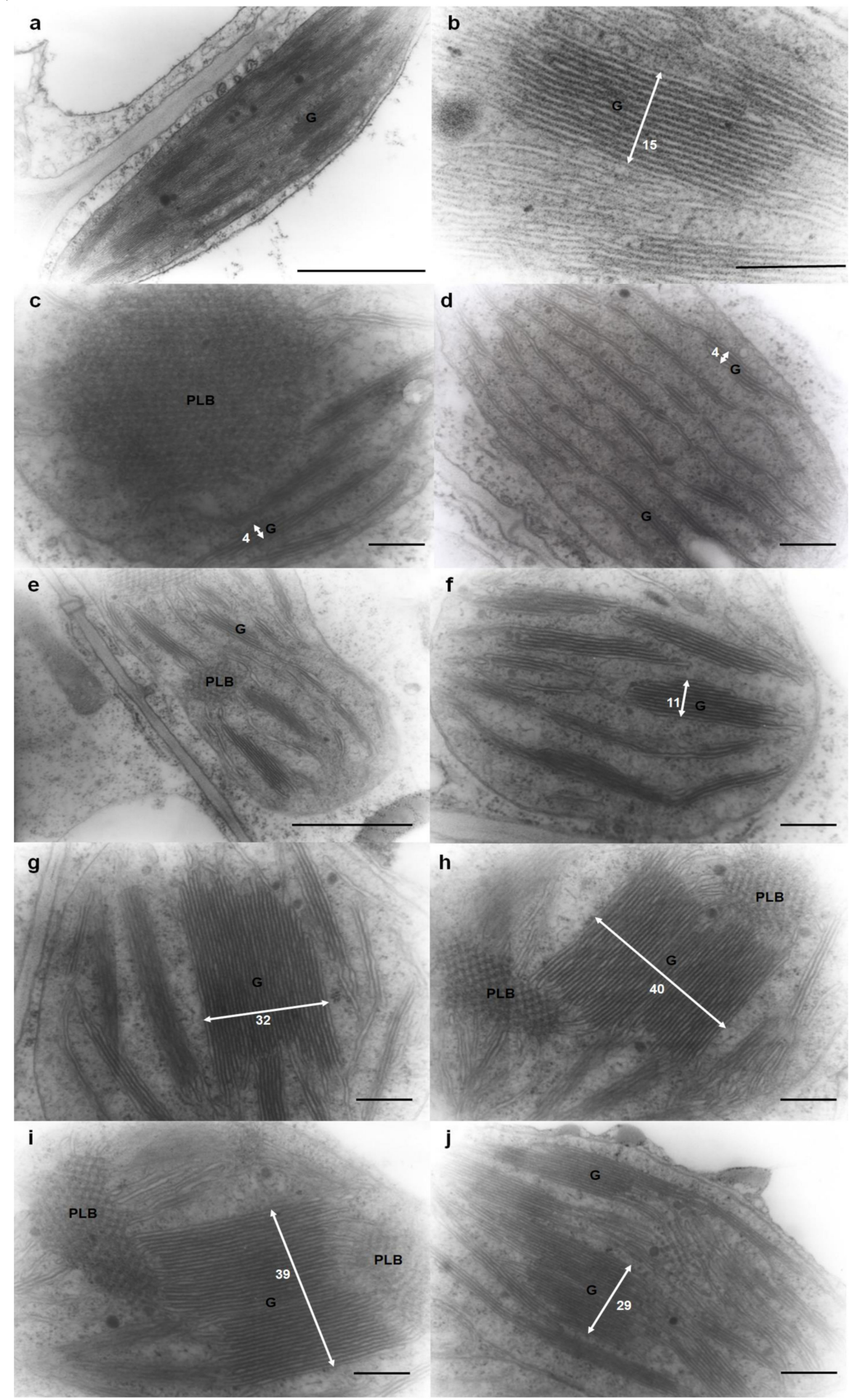

Figure 7. Ultrastructure and morphology of thylakoid membranes of mesophyll cells from newly developed leaves of Pachira macrocarpa plants fed various concentrations of glucose in complete darkness. The central part of a leaf was sampled. Panels $(\mathbf{a}, \mathbf{b})$ were under natural illumination conditions without glucose. Panels $(\mathbf{c}, \mathbf{d})$ were dark-grown control plants. Panels $(\mathbf{e}, \mathbf{f})$ were darkgrown plants with $2 \%$ glucose. Panels $(\mathbf{g}, \mathbf{h})$ were dark-grown plants with $4 \%$ glucose. Panels $(\mathbf{i}, \mathbf{j})$ were dark-grown plants with $6 \%$ glucose. Abbreviations: G, grana; PLBs, prolamellar bodies. Bars in $(\mathbf{a}, \mathbf{e})=1 \mu \mathrm{m}$; Bars in $(\mathbf{b}-\mathbf{d}, \mathbf{f}-\mathbf{j})=200 \mathrm{~nm}$. Numbers of thylakoid layers are indicated by white numbers. 


\section{Discussion}

Chlorophyll is the main green pigment in plants. Angiosperm Chl synthesis, including a light-requiring step, the NADPH-POR-Pchlide complex, can catalyze Pchlide to Chlide in light conditions [1]. When higher plants are cultured in dark conditions for a long time, Chls cannot be synthesized, and the color of mature leaves becomes pale-yellow, a phenomenon observed in dark-grown control mature leaves (Figure 1b). However, when fed glucose, green pigment contents of young and mature leaves were only upregulated for 2 weeks, and then were downregulated (Figure 3). This might be because glucose delayed the degradation of $\mathrm{Chl}$ and increased other green pigments (e.g., porphyrins and pyrroles) that accumulated in these leaves. The slope of the decrease of green pigments synthesis of pre-illuminated young leaves (Figure 3b) was less than that of pre-illuminated mature leaves (Figure 3a), indicating that the age of the leaves affected the ability to synthesize green pigments in complete darkness. The green color of leaves indicated green pigment contents, which only increased in glucose-fed plants, but not in glucose-starved plants (Figures 1, 3 and 4), implying that glucose affected ChlP development and green pigment contents in dark-grown plants.

Glucose feeding can upregulate ABA sensitivity and accelerate senescence in darkgrown young and mature leaves of angiosperms [8]. In addition, a high sugar level can induce ABA synthesis and repress some photosynthetic gene expressions and leaf senescence $[9,17]$. ABA also plays an inhibitory role in cotyledon de-etiolation and photomorphogenesis in tomato seedlings [18] (Humplík et al. 2015). In our study, the trend of green pigment contents in young and mature leaves was to initially increase and then decrease (Figure 3), which implies that ABA induced senescence in these leaves, or the ability to synthesize green pigments was lost. In addition, the transition point of green pigment contents differed in young leaves (6 weeks) and mature leaves (4 weeks), which hints that the age of the leaves affected their sensitivity to ABA. Sugars induce ABA signals during vegetative development, resulting in delaying in bud development $[19,20]$, and this effect can also be seen in Figure 6, suggesting that high concentrations of glucose negatively regulated plant growth. However, the color of newly developed leaves grown in the dark with glucose treatments was green, and the green pigments increased as the glucose concentration increased (Figure 4). Plant pigment molecules are non-covalently associated with polypeptides to form several pigment-protein complexes located in thylakoid membranes, and some of the pigments are unstable in the absence of apoproteins [21]

In TEM studies, PLBs and grana appeared in etio-ChlPs, a transient state between etioplasts and ChlPs (Figure 7g-j). These two morphological characteristics were generated in different conditions. PLBs appeared in dark-grown plants and gradually transformed to thylakoid membranes with light irradiation, whereas thick grana appeared in shade-grown plants so that they could capture more light energy. Etio-ChlPs in angiosperms were also observed in sunflower cotyledons grown in a light condition [22], in leaf primordia after 1 week of dark forcing of closed buds of the horse chestnut [23], and in dark-grown leaves and newly developed leaves of sugarcane [24]. These morphological characteristics were similar to dark-grown plants fed $2 \%$ glucose (Figure $7 \mathrm{e}, \mathrm{f}$ ), indicating that PLBs and grana could be observed in angiosperms. However, thicker grana in dark-grown plants fed $4 \%$ and $6 \%$ glucose (Figure $7 \mathrm{~g}-\mathrm{j}$ ) were only observed in our study. In dark-grown gymnosperm seedlings, etio-ChlPs were observed, and many photosynthetic proteins still maintained high expression levels [25].

Thylakoid formations were extruded and extended from the PLB structure, and grana were formed from thylakoid stacking. When plants were cultured in a shaded environment, ChlPs generated thicker grana and more light-harvesting complexes (LHCs) compared to plants cultured in light conditions [26,27]. Etio-ChlP transformations are light dependent in higher plants, and in etioplasts, NADPH, Pchlide, and LPOR are enclosed in PLBs [28]. There is a tight correlation between Pchlide metabolites to Chlide and PLB transformation into thylakoids and grana. Morphological changes were rapid: after $16 \mathrm{~min}$ of light irradiation, almost all PLBs had been transformed into thylakoids [29]. Therefore, in our 
study, Figure 1 photographs were taken within $15 \mathrm{~s}$ after exposure to light, before PLB structural changes were induced.

Light and glucose cause a number of hormone-like responses in a variety of eukaryotes, affecting various gene expressions and developmental processes [30,31]. Proteomic studies showed that many $\mathrm{Chl}$ synthesis-related proteins, photosynthetic light reaction proteins, and repair proteins exhibited increased expression levels in a dark-growing condition for $16 \mathrm{~h}$ [32]. Several enzymes in the Calvin cycle and POR accumulated, but their activities were inhibited during a dark-growth condition [32], and de-etiolation of plants is lightdependent and signal regulated [33-35], resulting in large PLBs were observed in this dark-grown angiosperm (Figure 7).

In morphological studies, plant hormones also control the signaling network though HY5 and COP1 interactions, including brassinosteroid, gibberellins [36-38], auxins, cytokinins [39], and ABA [40]. Only cytokinins and ABA positively regulate Chl synthesis. In the ABA pathway, ABI4-HY5 can serve as a regulatory switch for light control of Arabidopsis development $[41,42]$. On the other hand, cytokinins promote root greening via the HY5, ARR1, and ARR12 pathways, and these pathways are repressed by auxins [39].

\section{Conclusions}

Our study provides a beginning for studying leaf greening and thylakoid development in newly developed leaves of dark-grown plants. Glucose can induce newly developed leaves of $P$. macrocarpa to turn green under completely dark conditions. However, the numbers of buds decreased, and green pigments accumulated in the first 2 weeks, then degraded in the following weeks in pre-illuminated young and mature leaves. TEM images showed that thick grana connected to PLBs were found in glucose-fed newly developed leaves cultured in completely dark conditions. We concluded that glucose can regulate the dark synthesis of green pigments in P. macrocarpa.

Author Contributions: T.-C.L. and C.-M.Y. designed the experiments, T.-C.L. and K.-H.L. wrote the paper; M.-Y.H. and T.-C.L. conducted experiments and analyzed the data. All authors have read and agreed to the published version of the manuscript.

Funding: This work was financially supported by the "Innovation and Development Center of Sustainable Agriculture" from the Featured Areas Research Center Program within the Higher Education Sprout Project by the Ministry of Education (MOE) of Taiwan.

Data Availability Statement: Not applicable.

Conflicts of Interest: The authors declare that there is no competing interest and that the articles submitted without any commercial or economic interest that could be generated as a potentialconflict of interest.

\section{Abbreviations}

$\begin{array}{ll}\text { ABA } & \text { Abscisic acid } \\ \text { Chl } & \text { Chlorophyll } \\ \text { Chlide } & \text { Chlorophyllide } \\ \text { ChlP } & \text { Chloroplast } \\ \text { CLH } & \text { Chlorophyllase } \\ \text { DPOR } & \text { Dark protochlorophyllide oxidoreductase } \\ \text { LPOR } & \text { Light-dependent Pchlide oxidoreductase } \\ \text { NADPH } & \text { Nicotinamide adenine dinucleotide phosphate } \\ \text { Pchlide } & \text { Protochlorophyllide } \\ \text { PLB } & \text { Prolamellar body } \\ \text { PmCLH } & \text { Pachira macrocarpa CLH } \\ \text { PYL8 } & \text { Pyrabactin resistance-like } 8 \\ \text { SDS } & \text { Sodium dodecylsulfate } \\ \text { TEM } & \text { Transmission electronic microscopy }\end{array}$




\section{References}

1. Heyes, D.J.; Ruban, A.V.; Hunter, C.N. Protochlorophyllide oxidoreductase: "Dark" reactions of a light-driven enzyme. Biochemistry 2003, 42, 523-528. [CrossRef] [PubMed]

2. Reinbothe, C.; El Bakkouri, M.; Buhr, F.; Muraki, N.; Nomata, J.; Kurisu, G.; Fujita, Y.; Reinbothe, S. Chlorophyll biosynthesis: Spotlight on protochlorophyllide reduction. Trends Plant Sci. 2010, 15, 614-624. [CrossRef]

3. Breznenová, K.; Demko, V.; Pavlovič, A.; Gálová, E.; Balážová, R.; Hudák, J. Light-independent accumulation of essential chlorophyll biosynthesis- and photosynthesis-related proteins in Pinus mugo and Pinus sylvestris seedlings. Photosynthetica 2010, 48, 16-22. [CrossRef]

4. Masuda, T.; Takamiya, K. Novel insights into the enzymology, regulation and physiological functions of light-dependent protochlorophyllide oxidoreductase in angiosperms. Photosynth. Res. 2004, 81, 1-29. [CrossRef]

5. Schoefs, B.; Franck, F. Protochlorophyllide reduction: Mechanisms and evolution. Photochem. Photobiol. 2003, $78,543-557$. [CrossRef]

6. Xiong, W.; Li, X.; Xiang, J.; Wu, Q. High-density fermentation of microalga Chlorella protothecoides in bioreactor for microbio-diesel production. Appl. Microbiol. Biotechnol. 2008, 78, 29-36. [CrossRef]

7. Harun, R.; Singh, M.; Forde, G.M.; Danquah, M. Bioprocess engineering of microalgae to produce a variety of consumer products Renew. Sustain. Energy Rev. 2010, 14, 1037-1047. [CrossRef]

8. Häusler, R.E.; Heinrichs, L.; Schmitz, J.; Flügge, U. How sugars might coordinate chloroplast and nuclear gene expression during acclimation to high light intensities. Mol. Plant 2014, 7, 1121-1137. [CrossRef]

9. Lee, H.N.; Lee, K.H.; Kim, C.S. Abscisic acid receptor PYRABACTIN RESISTANCE-LIKE 8, PYL8, is involved in glucose response and dark-induced leaf senescence in Arabidopsis. Biochem. Biophys. Res. Commun. 2015, 463, 24-28. [CrossRef]

10. Heinrichs, L.; Schmitz, J.; Flügge, U.I.; Häusler, R.E. The mysterious rescue of adg1-1/tpt-2-An Arabidopsis thaliana double mutant impaired in acclimation to high light-By exogenously supplied sugars. Front. Plant Sci. 2012, 3, 265. [CrossRef]

11. Packer, N.; Adamson, H. Incorporation of 5-aminolevulinic acid into chlorophyll in darkness in barley. Physiol Plant 1986, 68, 222-230. [CrossRef]

12. Walmsley, J.; Adamson, H. Gabaculine inhibition of chlorophyll synthesis in light and darkness in intact barley (Hordeum vulgare) seedlings. Plant Sci. 1990, 68, 65-70. [CrossRef]

13. Chen, C.M.; Chao, P.Y.; Huang, M.Y.; Yang, J.H.; Lin, K.H.; Yang, C.M. Chlorophyllase activity in green and non-green tissues of variegated plants. S. Afr. J Bot. 2012, 81, 44-49. [CrossRef]

14. Chen, C.M.; Yang, J.H.; Liu, C.H.; Lin, K.H.; Yang, C.M. Molecular, structural, and phylogenetic characterization of two chlorophyllase isoforms in Pachira macrocarpa. Plant Syst. Evol. 2014, 300, 633-643. [CrossRef]

15. Johnson, C.M.; Stout, P.R.; Broyer, T.C.; Carlton, A.B. Comparative chlorine requirements of different plant species. Plant Soil 1957, 8, 337-353. [CrossRef]

16. Porra, R.J.; Thompson, W.A.; Kriedelman, P.E. Determination of accurate extraction and simultaneously equation for assaying chlorophyll $\mathrm{a}$ and $\mathrm{b}$ extracted with different solvents: Verification of the concentration of chlorophyll standards by atomic absorption spectroscopy. Biochim. Biophys. Acta 1989, 975, 384-394. [CrossRef]

17. Rook, F.; Hadingham, S.A.; Bevan, M.W. Sugar and ABA response pathways and the control of gene expression. Plant Cell Environ. 2006, 29, 426-434. [CrossRef]

18. Humplík, J.F.; Turečková, V.; Fellner, M.; Bergougnoux, V. Spatio-temporal changes in endogenous abscisic acid contents during etiolated growth and photomorphogenesis in tomato seedlings. Plant Signal Behav. 2015, 8, e1039213. [CrossRef]

19. Arenas-Huertero, F.; Arroyo, A.; Zhou, L.; Sheen, J.; León, P. Analysis of Arabidopsis glucose insensitive mutants, gin5 and gin6, reveals a central role of the plant hormone ABA in the regulation of plant vegetative development by sugar. Genes Dev. 2000, 14, 2085-2096.

20. Matsoukas, I.G. Interplay between sugar and hormone signaling pathways modulate floral signal transduction. Front. Genet. 2014, 5, 218. [CrossRef]

21. Eichacker, L.; Paulsen, H.; Rüdiger, W. Synthesis of chlorophyll a regulates translation of chlorophyll a apoproteins P700, CP47, CP43 and D2 in barley etioplasts. Eur. J. Biochem. 1992, 205, 17-24. [CrossRef]

22. Katalin, S.; Beáta, V.; Éva, H.; Béla, B. Etiolation symptoms in sunflower (Helianthus annuus) cotyledons partially covered by the pericarp of the achene. Ann. Bot. 2007, 99, 857-867.

23. Solymosi, K.; Bóka, K.; Böddi, B. Transient etiolation: Protochlorophyll(ide) and chlorophyll forms in differentiating plastids of closed and breaking leaf buds of horse chestnut (Aesculus hippocastanum). Tree Physiol. 2006, 26, 1087-1096. [CrossRef]

24. Laetsch, W.M.; Price, I. Development of the dimorphic chloroplasts of sugar cane. Am. J. Bot. 1969, 56, 77-87. [CrossRef]

25. Brzezowski, P.; Richter, A.S.; Grimm, B. Regulation and function of tetrapyrrole biosynthesis in plants and algae. Biochim. Biophys. Acta 2015, 1847, 968-985. [CrossRef]

26. Pribil, M.; Labs, M.; Leister, D. Structure and dynamics of thylakoids in land plants. J. Exp. Bot. 2014, 65, 1955-1972. [CrossRef]

27. Rast, A.; Heinz, S.; Nickelsen, J. Biogenesis of thylakoid membranes. Biochim. Biophys. Acta. 2015, 1847, 821-830. [CrossRef]

28. Sundqvist, C.; Dahlin, C. With chlorophyll pigments from prolamellar bodies to light-harvesting complexes. Physiol. Plant 1997, 100, 48-759. [CrossRef]

29. Philippar, K.; Geis, T.; Ilkavets, I.; Oster, U.; Schwenkert, S.; Meurer, J.; Soll, J. Chloroplast biogenesis: The use of mutants to study the etioplast-chloroplast transition. Proc. Natl. Acad. Sci. USA 2007, 104, 678-683. [CrossRef] 
30. Rolland, F.; Winderickx, J.; Thevelein, J.M. Glucose-sensing mechanisms in eukaryotic cells. Trends Biochem. Sci. 2001, 26, 310-317. [CrossRef]

31. Sheen, J.; Zhou, L.; Jang, J.C. Sugars as signaling molecules. Curr. Opin. Plant Biol. 1999, 2, 410-418. [CrossRef]

32. Wang, J.; Yu, Q.; Xiong, H.; Wang, J.; Chen, S.; Yang, Z.; Dai, S. Proteomic insight into the response of Arabidopsis chloroplasts to darkness. PLoS ONE 2016, 11, e0154235. [CrossRef]

33. Chi, W.; Sun, X.; Zhang, L. Intracellular signaling from plastid to nucleus. Annu. Rev. Plant Biol. 2013, 64, 559-582. [CrossRef]

34. Nott, A.; Jung, H.S.; Koussevitzky, S.; Chory, J. Plastid-to-nucleus retrograde signaling. Annu. Rev. Plant Biol. 2006, 57, 739-759. [CrossRef]

35. Woodson, J.D.; Chory, J. Coordination of gene expression between organellar and nuclear genomes. Nat. Rev. Genet. 2008, 9, 383-395. [CrossRef] [PubMed]

36. Bai, M.Y.; Shang, J.X.; Oh, E.; Fan, M.; Bai, Y.; Zentella, R.; Sun, T.P.; Wang, Z.Y. Brassinosteroid, gibberellin and phytochrome impinge on a common transcription module in Arabidopsis. Nat. Cell Biol. 2012, 14, 810-817. [CrossRef] [PubMed]

37. Feng, S.; Martinez, C.; Gusmaroli, G.; Wang, Y.; Zhou, J.; Wang, F.; Chen, L.; Yu, L.; Iglesias-Pedraz, J.M.; Kircher, S.; et al. Coordinated regulation of Arabidopsis thaliana development by light and gibberellins. Nature 2008, 451, 475-479. [CrossRef] [PubMed]

38. Jiao, Y.; Lau, O.S.; Deng, X.W. Light-regulated transcriptional networks in higher plants. Nat. Rev. Genet. 2007, 8, 217-230. [CrossRef]

39. Kobayashi, K.; Ohnishi, A.; Sasaki, D.; Fujii, S.; Iwase, A.; Sugimoto, K.; Masuda, T.; Wada, H. Shoot removal induces chloroplast development in roots via cytokinin signaling. Plant Physiol. 2017, 173, 2340-2355. [CrossRef] [PubMed]

40. Chen, H.; Zhang, J.; Neff, M.M.; Hong, S.W.; Zhang, H.; Deng, X.W.; Xiong, L. Integration of light and abscisic acid signaling during seed germination and early seedling development. Proc. Natl. Acad. Sci. USA 2008, 105, 4495-4500. [PubMed]

41. Gangappa, S.N.; Botto, J.F. The multifaceted roles of HY5 in plant growth and development. Mol. Plant 2016, 9, 1353-1365. [CrossRef] [PubMed]

42. Xu, X.; Chi, W.; Sun, X.; Feng, P.; Guo, H.; Li, J.; Lin, R.; Lu, C.; Wang, H.; Leister, D.; et al. Convergence of light and chloroplast signals for de-etiolation through ABI4-HY5 and COP1. Nat. Plants 2016, 2, 16066. [CrossRef] [PubMed] 